\title{
Psychosocial Problems and Academic Achievement of Deviant Pupils in Basic Schools in Oyo State, Nigeria
}

\author{
Oluwafeyisayomi Ayinde \\ Department of Social Sciences Education, Faculty of Education, University of Ilorin, Nigeria, \\ sayomiayinde@gmail.com
}

\section{F. A. O. Olasehinde-Williams}

Prof., Department of Social Sciences Education, Faculty of Education, University of Ilorin, Nigeria, olabisi@unilorin.edu.ng

Children with deviant behaviours display difficulties adjusting to the classroom environment and also show social skill deficits, and low academic performance. This paper examined the psychosocial problems and academic achievement of deviant pupils in basic schools in Oyo State, Nigeria. This study was a descriptive survey research method of the correlational type. Three purposes and three research questions were raised and two hypotheses were tested. The sample for this study comprised 171 deviant pupils in public basic six in the two selected senatorial districts. Twenty Basic Schools were selected from the four Local Government Areas using proportionate random sampling technique. Three instruments were used for this study: a checklist on the types of deviant behaviour, a researcher-designed questionnaire titled "Psychosocial Scale (PS)" and an Academic Achievement Test (AAT). The findings of the study were that: the most prevalent deviant behaviour among deviant pupils was coming late to school. There was no significant difference in the psychosocial problem and academic achievement of male and female deviant pupils in Basic Schools in Oyo state. It was recommended that parents should ensure that their children leave home as early as possible in order not to get late to school and also, punishment should be melted out to late comers in order to reduce the rate at which pupils come late to school, teachers should find out why pupils come late to school either by raising during Parent-Teachers' Association meeting and they dialogue and discuss the way out of it with the parents. Teacher should have positive attitude to deviant pupils because it helps to them have positive feelings about themselves. Deviant behaviours among pupils, if not checked, can lead to societal vices, because of this, seminars should be organized for teachers to enhance their knowledge on effective behaviour modification techniques. The schools should provide record book to keep details of cases and to monitor pupils' progressive behaviour changes and learning needs in order to know whether the rate of deviant behaviour is reducing or increasing.

Keywords: psychosocial problems, academic achievement, pupils, middle basic, deviant behaviour

\section{INTRODUCTION}

In recent years, incidences of deviant behaviours among pupils have become more serious. There have been instances of pupils bullying others and threatening teachers have become common occurrence in schools. It seems that schools are helpless in matter of pupils' deviant behaviours and the educational authority does not have effective measures put in place to curb the problems. Self-esteem is how we see or value ourselves. It involves the generative aspect of the self, with constructions of past and

Citation: Ayinde, O., \& Olasehinde-Williams, F. A. O. (2020). Psychosocial Problems and Academic Achievement of Deviant Pupils in Basic Schools in Oyo State, Nigeria. Anatolian Journal of Education, 5(1), 41-46. https://doi.org/10.29333/aje.2020.514a 
future selves allowing the evaluation not just of current relational value, but expected value in future interactions (Leary \& MacDonald, 2003). Self-efficacy is best conceived as a differentiated set of selfbeliefs specific to different areas of functioning (e.g., social self-efficacy, academic self-efficacy); and is therefore considered a domain-specific concept as no person can feel competent at all tasks (Bandura, 1997). Uwaifo (2008) asserted that the family lays the psychological, moral, spiritual foundations in the overall development of the child while the significant role of this cannot be overemphasized. The family is a group of people recognized by their community as related to one another by ties of marriage. In common usage, a family is the group which lives in a house under a single head. A parent is a model towards their children. Peer pressure is defined as when people of your own age encourage or urge you to do something or to keep from doing something else, no matter if you personally want to do it or not (Ryan, 2000).

Physical punishment violates pupils' human rights and only temporarily curbs surface behaviours. The issue of deviance is being discussed on television, radio, newspapers and journals and recently on the internet. Several researches have been carried out on deviance. Fareo (2013) carried out a research on Truancy and Academic Performance of Secondary School Students in South-western Nigeria: Implications for Counselling, it examined the relationship between school physical environment and truancy behavior among students. The study revealed that there was a significant relationship between truancy and academic performances of students; there was not a significant relationship between the school physical environment and truancy behavior among students; there was not a significant difference between the academic performance of male and female truants. However, there was a significant difference between male and female manifestation of truancy behavior. The study concluded that truancy hindered effective learning and could lead to poor academic performance. Ogunsola, Osuolale and Ojo (2014) studied on parental and related factors affecting students' academic achievement in Oyo State. The sample consisted of senior secondary school students in Ibadan North Local Government Area, among all the factors that affect academic achievements of students, the study found the parent attitude, support or contributions to be highly significant predictor of students' academic outcomes. Also, Adekoya-Olapade (2015) carried out research on effects of truancy among primary school pupils in Oyo State, Nigeria and the possible remedies, one of the findings of the study showed that pupils from both Christian and Muslim homes were not exempted from truancy, male and female rate of truancy were of the same rate. Both male and female were indulging in truancy, pupils from private and public schools indulged in truancy and there were no differences in their practices from both schools.

From the literature reviewed it was discovered that there was little or no study carried out on psychosocial problems and academic achievement of deviant pupils in basic schools in Oyo State. Therefore, the researchers deem it fit to investigate psychosocial problems and academic achievement of deviant pupils in basic schools in Oyo State, in order to fill the gap in knowledge.

\section{Purpose of the Study}

The general purpose of the study was to find out the psychosocial problems and academic achievement of deviant pupils in basic schools in Oyo State. The specific purposes were to examine:

1. type of deviant behaviour prevalent among deviant pupils in Basic Schools in Oyo State;

2. difference in the psychosocial problems of male and female deviant pupils in Basic Schools in Oyo State;

3. difference in the academic achievement of male and female deviant pupils in Basic Schools in Oyo State.

\section{Research Questions}

The following research questions were formulated for this study:

1. What are the prevalent types of deviant behaviour among pupils in Basic Schools in Oyo State? 
2. Is there any difference in the psychosocial problems of male and female deviant pupils in Basic Schools in Oyo State?

3. What is the difference in the academic achievement of male and female deviant pupils in Basic Schools in Oyo State?

\section{Research Hypotheses}

The following research hypotheses were tested in this study:

$\mathbf{H}_{\mathbf{O} 1}$ : There is no significant difference in the psychosocial problems of male and female deviant pupils in Basic Schools in Oyo State.

$\mathbf{H}_{\mathbf{O} 2}$ : There is no significant difference in the academic achievement of male and female deviant pupils in Basic Schools in Oyo State.

\section{METHOD}

The research designed employed for this study was a descriptive survey method of the correlational type. It was assumed suitable because it is the statistical test used to determine the tendency or pattern for two or more variables or sets of data to vary consistently. This study examined the psychosocial problems and academic achievement of deviant pupils in basic schools in Oyo State; because literatures reviewed show that similar studies are yet to be carried out in Oyo State.

The study was restricted to pupils in public schools in Oyo State that have shown records of cases of deviant behaviours are rampant in public schools than private schools The sample was drawn from basic six deviant pupils because pupils at this stage should be able to make distinction between what is good and bad. The sample was made up of 171 pupils which consist of 105 males, 66 females. The sampling technique used for selecting the sample for this study was Multi-stage sampling technique. The three instruments used for this study were: a checklist on types of deviant behaviour, a researcherdesigned questionnaire titled "Psychosocial Scale (PS)" and an Academic Achievement test.

The Checklist: consists of five items to elicit information on the type of deviant behaviour prevalent among deviant pupils. The items 1-5 were rated using a four-point Likert-type scale of 'Always', 'Sometimes', 'Occasionally' and 'Never'. Always-4 points, Sometimes-3 points, Occasionally-2 points, Never-1 point. Mean rating was used to analysed it.

The Questionnaire: was divided into two sections: A and B. Section A consist of items on personal information such as: age, and sex; section B consist of 20 items that elicit information on Psychosocial Variables viz: Self-esteem, Self-efficacy, Family and Peer relationships with a four-point Likert-type scale of 'Strongly Agree', 'Agree', 'Disagree' and 'Strongly Disagree'. Strongly Agree -4 points, Agree -3 points, Disagree -2 points, Strongly Disagree -1 point. The benchmark for each group in this section was 15; any score below 15 is a psychosocial problem. The highest score a pupil can get in each group is 20 (5 items $\mathrm{x} 4$ responses) while the lowest score is 10 . Minus the lowest score from the highest score and divide the answer by two since the researcher is interested in two levels of psychosocial problem (high or low).

The Academic Achievement Test: The test contains 20 questions drawn from Common Entrance Examination past questions of 2001/2002 and 2015/2016 Sessions on English Language and was administered to the deviant pupils in order to measure their academic performance. The past questions were chosen because they go in-line with the curriculum. Scores from 50 and above means the pupils passed while scores from 49 downward means that the pupils failed. The test is to be completed within 20 minutes and each question carry 5marks. The reliability of the instruments was established, test retest method was used. The researcher selected one primary school in Atiba Local Government Area of Oyo State with 10 respondents that did not participate in the final research and selected Basic six 
pupils that had the same characteristics with the target population, where the checklist, questionnaire and the academic achievement test were administered twice, within an interval of three weeks. The data collected from both administrations were analysed using Pearson Product Moment Correlation of Co-efficient (Pearson ' $r$ ') to ascertain its reliability index. The reliability index of The Checklist on types of Deviant Behaviour was found to be 0.67, also, the reliability index of Psychosocial Scale was found at 0.75 , while the reliability index of academic performance test was found at 0.72 . The independent t-test was used to test research hypothesis One and Two at 0.05 significant level.

\section{FINDINGS}

Research Question 1: What is the type of deviant behaviour prevalent among pupils in Basic Schools in Oyo State?

In order to answer this research question, respondents' responses on the type of deviant behaviour prevalent checklist were collated. Researcher was required to rate each deviant behaviour in order of magnitude among deviant pupils. The mean ratings were then computed and used to rank each behaviour. The summary of the rankings is presented in Table 1.

Table 1

Rank Order of the Types of Deviant Behaviours Prevalent among Deviant Pupils in Basic Schools in Oyo State

\begin{tabular}{llcc}
\hline S/N & Types of Deviant Behaviours & Mean & Rank \\
\hline 1. & I absent myself from school without permission from my parents or class teachers & 2.30 & $2^{\text {nd }}$ \\
2. & I cheat during tests or examinations & 2.01 & $4^{\text {th }}$ \\
3. & I come late to school & 2.37 & $1^{\text {st }}$ \\
4. & I write on school desks, walls, chairs & 2.19 & $3^{\text {rd }}$ \\
5 & I do fight with my class mates & 2.01 & $4^{\text {th }}$ \\
\hline
\end{tabular}

Table 1 indicates that 171 respondents participated in this study and agreed with the identified type of deviant behaviours prevalent among pupils in Basic Schools in Oyo State. Behaviours ranked as the most prevalent among deviant pupils in middle basic schools in Oyo State was 'I come late to school' which had a mean score of 2.37 (1st), while the next to this 'I absent myself from school without permission from my parents or class teachers' which had a mean score of $2.30\left(2^{\text {nd }}\right)$, 'I write on school desks, walls, chairs' which had a mean score of $2.19\left(3^{\text {rd }}\right)$, 'I cheat during tests or examinations'; and 'I do fight with my class mates' ranked the lowest with a mean score of $2.01\left(4^{\text {th }}\right)$.

Two research hypotheses were postulated and were tested using the t-test statistics at 0.05 level of significance.

$\mathbf{H}_{\mathbf{O} 1}$ : There is no significant difference in the psychosocial problems of male and female deviant pupils in Basic Schools in Oyo state.

In order to test this research hypothesis, deviant pupils' responses to the psychosocial items were collated based on gender. The mean scores of both groups were then compared using t-test statistics. Summary of the analysis is presented in Table 2.

Table 2

t-test Analysis of the Difference in the Psychosocial Problems of Male and Female Deviant Pupils

\begin{tabular}{llllllll}
\hline Gender & No & Mean & Std & df & Cal.t & Sig.(2-tailed) & Decision \\
\hline Male & 105 & 59.86 & 3.68 & & & & $\mathrm{H}_{01}$ \\
Female & 66 & 57.68 & 3.93 & & & & Accepted \\
\hline
\end{tabular}

$\rho>0.05$ 
As shown on Table 2, the calculated t-value was 1.83 while the p-value is 0.07 at 0.05 level of significance. On this basis, the null hypothesis one was accepted. This means that there was no significant difference in the psychosocial problems of male and female deviant pupils in Middle Basic Schools in Oyo state, Nigeria. The reason was that the p- value (0.07) was greater than 0.05 alpha level (i.e. $0.07>0.05$ ).

$\mathbf{H}_{\mathbf{O} 2}$ : There is no significant difference in the academic achievement of male and female deviant pupils in Basic Schools in Oyo State.

In order to test this research hypothesis, respondents' scores on the Academic Achievement Test were collated based on gender. The data collected were subjected to t-test analysis and the summary of the analysis shown in Table 3.

Table 3

t-test Analysis of the Difference in the Academic Achievement of Male and Female Deviant Pupils in Basic Schools in Oyo State

\begin{tabular}{llllllll}
\hline Gender & No & Mean & Std & df & Cal.t & Sig.(2-tailed) & Decision \\
\hline Male & 105 & 32.48 & 12.88 & & & & $\mathrm{H}_{02}$ \\
Female & 66 & 35.76 & 15.47 & & & & \\
\hline$\rho>0.05$ & & & & & & & \\
\hline
\end{tabular}

As shown on Table 3, the obtained Cal.t-value of 1.51 while the p-value was $0.14>0.05$. Since 0.14 is greater than 0.05 alpha level, hypothesis two was accepted. This indicates that there was no significant difference in the academic achievement of male and female deviant pupils in Middle Basic Schools in Oyo State, Nigeria.

\section{DISCUSSION}

A finding of this study revealed that the greatest type of deviant behaviour prevalent among deviant pupils in basic schools in Oyo State was coming late to school with the mean score of 2.37. A possible reason for coming late to school to be the greatest type of deviant behaviour could be because deviant pupils roam about after leaving home before they go to school. This finding is in consonance with that of Adekoya-Olapade (2015) who found that male and female pupils' rates of truancy were about the same. Both male and female pupils indulged in truancy, pupils from private and public schools indulged in truancy and there were no differences in their practices in both schools. Osarenren (1997) opined that, as should be expected, truancy and absenteeism in particular affect the academic performance of pupils.

Another finding revealed that there was no significant difference in the psychosocial problems of male and female deviant pupils in Basic Schools in Oyo state, $(0.07>0.05)$. This shows that both male and female deviant pupils in the schools had psychosocial problem. A possible reason could be because both male and female deviant pupils have negative perception about themselves. This finding contradicted the findings of Heimer (1996) who found out that antisocial behaviour was more consistent with behaviour considered appropriate for boys and inconsistent with behaviour considered appropriate for girls. On the contrary, Storvoll and Wichstrom (2002) found out that males are more exposed to risk factors for delinquency.

Another finding revealed that there was no significant difference in the academic achievement of male and female deviant pupils in Basic Schools in Oyo State, ( $p$-value $=0.14>0.05$ alpha level), probably because they were more preoccupied by behaviours that distracted their attention from academics. This finding is in agreement with that of Fareo (2013) who found out that there was no significant 
difference between the academic performance of truant male and female students in Southwestern, Nigeria.

\section{CONCLUSION}

Based on the findings of this study the following conclusions were drawn: the greatest type of deviant behaviour prevalent among deviant pupils in basic schools in Oyo State was coming late to school. There was no significant difference in the psychosocial problems of male and female deviant pupils in Basic Schools in Oyo State. There was no significant difference in the academic achievement of male and female deviant pupils in Basic Schools in Oyo State.

\section{RECOMMENDATIONS}

It was recommended that parents should ensure that their children leave home as early as possible in order not to get late to school and also, punishment should be melted out to late comers in order to reduce the rate at which pupils come late to school, teachers should find out why pupils come late to school either by raising during Parent-Teachers' Association meeting and they dialogue and discuss the way out of it with the parents. Teacher should have positive attitude to deviant pupils because it helps to them have positive feelings about themselves. Deviant behaviours among pupils, if not checked, can lead to societal vices, because of this, seminars should be organized for teachers to enhance their knowledge on effective behaviour modification techniques. The schools should provide record book to keep details of cases and to monitor pupils' progressive behaviour changes and learning needs in order to know whether the rate of deviant behaviour is reducing or increasing.

\section{REFERENCES}

Adekoya-Olapade, A. O. (2015). Effects of truancy among primary school pupils in Oyo State of Nigeria and the possible remedies. J. of Socio., Psych. and anthropology in Practice, 7(1), $10-21$.

Bandura, A. (1997). Self-efficacy: The exercise of control. New York: W. H. Freeman and Company

Fareo, D. O. (2013). Truancy and academic performance of secondary school students in Southwestern Nigeria: Implications for counseling. International Journal for Cross-Disciplinary Subjects in Education (IJCDSE), Special Issue, 3(2), 14 - 26.

Heimer, K. (1996). Gender, interaction, and delinquency: Testing a theory of differential social control. Social Psychology Quarterly, 59, 39 - 61.

Leary, M. R., \& MacDonald, N. R. (2003). The evolution of the human self: Tracing the natural history of self-awareness. Journal for the Theory of Social Behavior, 33, 365 - 404.

Ogunsola, O. K., Osuolale, A. K., \& Ojo, A. O. (2014). Parental and related factors affecting students' academic achievement in Oyo State, Nigeria. International Journal of Social, Behavioral, Educational, Economic, Business and Industrial Engineering 8(9), 3065 - 3072.

Osarenre, N. (1997). Child development and personality. Lagos: Hiwits Press, Nigeria.

Ryan, A. M. (2000). Peer groups as a context for the socialization of adolescents' motivation, engagement, and achievement in school. Educational Psychologist, 35, $101-112$.

Storvoll, E., \& Wichstrom, L. (2002). Do the risk factors associated with conduct problems in adolescents vary according to gender? Journal of Adolescent, 25(2), 183-202.

Uwaifo V. O. (2008). The effects of family structure and parenthood on the academic performance of Nigerian University Students. Home Community Science, 2 (2), 121 - 124. 